\title{
MicroRNAs as the critical regulators of protein kinases in prostate and bladder cancers
}

\author{
Malihe Zangoue ${ }^{1}$, Amir Sadra Zangouei ${ }^{2}$, Majid Mojarrad ${ }^{3}$ and Meysam Moghbeli ${ }^{3^{*}}$ (1)
}

\begin{abstract}
Background: Bladder cancer (BCa) and prostate cancer ( $\mathrm{PCa}$ ) are frequent urothelial and genital malignancies with a high ratio of morbidity and mortality which are more common among males. Since BCa and PCa cases are mainly diagnosed in advanced stages with clinical complications, it is required to introduce the efficient early detection markers. Protein kinases are critical factors involved in various cellular processes such as cell growth, motility, differentiation, and metabolism. Deregulation of protein kinases can be frequently observed through the neoplastic transformation and tumor progression. Therefore, kinases are required to be regulated via different genetic and epigenetic processes. MicroRNAs (miRNAs) are among the critical factors involved in epigenetic regulation of protein kinases. Since miRNAs are noninvasive and more stable factors in serum and tissues compared with mRNAs, they can be used as efficient diagnostic markers for the early detection of PCa and BCa.

Main body: In present review, we have summarized all of the reported miRNAs that have been associated with regulation of protein kinases in bladder and prostate cancers.

Conclusions: For the first time, this review highlights the miRNAs as critical factors in regulation of protein kinases during prostate and bladder cancers which paves the way of introducing a noninvasive kinase-specific panel of miRNAs for the early detection of these malignancies. It was observed that the class VIII receptors of tyrosine kinases and non-receptor tyrosine kinases were the most frequent targets for the miRNAs in bladder and prostate cancers, respectively.
\end{abstract}

Keywords: Bladder cancer, Prostate cancer, MicroRNA, Kinase, Diagnosis

\section{Background}

High frequencies of double primary bladder and prostate cancers have been reported in several studies in which there were up to $70 \%$ of prostate cancers in bladder cancer patients [1]. Bladder cancer $(\mathrm{BCa})$ is the 12th most frequently diagnosed malignancy globally [2], with a global age-standardized rate of 10.1 and 2.5 per 100,000 for males and females, respectively [3]. A total of 81,190 newly diagnosed $\mathrm{BCa}$ cases and 17,240 deaths

\footnotetext{
*Correspondence: moghbelim@mums.ac.ir; Meysam_moghbeli@yahoo.com

${ }^{3}$ Department of Medical Genetics and Molecular Medicine, School

of Medicine, Mashhad University of Medical Sciences, Mashhad, Iran

Full list of author information is available at the end of the article
}

were recorded in 2018 in the USA [4]. BCa is the fourth most frequent malignancy and the second most prevalent tumor of the urinary tract after prostate cancer $(\mathrm{PCa})$ in the USA [4]. Considering tumor invasion, $\mathrm{BCa}$ is classified into muscle-invasive bladder cancer (MIBC) and non-muscle-invasive bladder cancer (NMIBC) [5]. Almost $25-30 \%$ of newly diagnosed $\mathrm{BCa}$ patients are MIBC and $15 \%$ of them show local or remote metastasis $[6,7]$. Based on the histopathological features, $\mathrm{BCa}$ is classified into squamous cell carcinoma, adenocarcinoma, and transitional cell carcinoma (TCC). TCC or urothelial carcinoma accounts for $90 \%$ of all BCa cases $[8,9]$. Intravesical chemotherapy or immunotherapy after transurethral resection is regarded as the standard 
treatment options for $\mathrm{BCa}$; however, the tumor recurrence within 5 years and treatment failure (which is seen in $30 \%$ of the patients) have challenged these approaches [10]. The cigarette smoking, gender, chemicals exposure, and water pollutants are some of the $\mathrm{BCa}$ risk factors. However, $\mathrm{BCa}$ is observed in a small fraction of individuals with the well-known risk factors that may refer to the contribution of various genetic and epigenetic alterations in BCa susceptibility $[11,12]$. PCa is the most frequently diagnosed malignancy and the second major cause of cancer mortality among males in western countries $[4,13]$. It is a highly heterogeneous malignancy in which some patients have an indolent manifestation $(90 \%$ 5 -year survival rate), while other patients experience an aggressive manifestation with local and distant metastases (5-year survival rate of 29\%) [14]. Age, race, familial history, environmental factors, and occupational exposures are considered as the main risk factors associated with PCa progression $[15,16]$. Protein kinases are a large family of proteins responsible for the phosphorylation of key proteins involved in cell proliferation, metabolism, differentiation, and apoptosis $[17,18]$. Regarding the pivotal regulatory roles of protein kinases in fundamental cellular processes, these factors should be strictly regulated to maintain the normal status inside the cells [19]. Protein kinases are categorized based on their amino acid targets to the tyrosine and serine/threonine kinases which can be located in membranes or cytoplasm. Deregulation of tyrosine kinases (TKs) is frequently observed during tumor progression and metastasis [20-22]. Therefore, TKs targeting and inhibition can improve the prognosis and clinical outcomes in cancer patients [23]. MiRNAs are small single-stranded non-coding RNAs (21-24 nucleotides in length), which negatively regulate the expression of their target mRNAs through translational inhibition or mRNAs degradation [24]. They are involved in regulation of important pathophysiological mechanisms including cell proliferation, differentiation, tumorigenesis, and angiogenesis [24, 25]. MiRNAs deregulations disrupt the normal modulatory functions of several signaling pathways that leads in tumor progression and metastasis [26]. There is a correlation between the tumor cell response to radiotherapy and miRNAs functions [27]. EGFR-tyrosine kinase inhibitors (TKIs) have a pivotal role in treatment and prognosis of cancer patients with epidermal growth factor receptor (EGFR) mutations. However, drug resistance limits the efficacy of EGFR-TKI in these patients. The ability of miRNAs to regulate many oncogenic pathways provides them as the novel prognostic biomarkers. Putative roles of miRNAs have been shown in regulation of EGFR-TKI resistance in EGFR-mutated tumors [28]. Exosomes can be used to deliver the miRNAs to EGFR expressing tumor cells [29].
MiRNAs are involved in regulation of cytochrome P450 as the main EGFR-TKI metabolizing enzyme to enhance drug-mediated toxicity and reduce pharmacological side effects [30, 31]. Aberrant expression of miRNAs is associated with progression of various malignancies including $\mathrm{PCa}$ and $\mathrm{BCa}[32,33]$. Since miRNAs are more stable than mRNAs in paraffin-embedded tissues and serum, they can be used as efficient noninvasive diagnostic markers in early detection of cancer. Although kinase inhibitors have been widely used as efficient options in urothelial tumor therapy, many tumors acquire resistance toward the protein kinase inhibitors. Therefore, it is required to clarify the molecular mechanisms which are involved in regulation of protein kinases. MicroRNAs have been introduced as important regulators of protein kinases during tumor progression and chemoresistance $[34,35]$. Therefore, in present review we have summarized all of the miRNAs which have been reported as the regulators of protein kinases during bladder and prostate cancer progressions (Table 1) (Fig. 1).

\section{Main text \\ Class I receptors of tyrosine kinases}

EGFR is a trans-membrane protein which belongs to the erbB family of receptors. Interaction of EGFR with its cognate EGF ligand induces intrinsic tyrosine kinase activity that subsequently activates intracellular signaling cascades [36]. EGFR is implicated in regulation of cell proliferation, angiogenesis, and tumor invasiveness [20]. It activates multiple signaling pathways including PI3K/ AKT and MAPK/ERK [37]. AKT has an oncogenic function by the induction of cell proliferation and apoptosis suppression [38]. It has been reported that the miR-133a and $m i R-133 b$ reduced tumor growth, cell proliferation, and migration through EGFR, $p-E R K, p-A K T$, and $M M P$ 2 targeting in $\mathrm{BCa}$ cells [39]. There was also a significant miR-135a downregulation in metastatic PCa tumors which was associated with advanced-stage tumor, higher Gleason score, and poorer prognosis. MiR-135a suppressed $\mathrm{PCa}$ cell proliferation and migration via targeting EGFR [40]. E-box binding homeobox 1 (ZEB1) is a zinc-finger transcription factor involved in DNA damage response [41, 42]. ZEB1 is phosphorylated and stabilized by ATM following radiotherapeutic-related DNA damage. It induces USP7 to deubiquitinate and stabilize the CHK1. Therefore, ZEB1 increases radioresistance by promotion of homologous recombination-mediated DNA repair [43]. A significant miR-875-5p downregulation was observed in prostate tumors compared with normal margins. There was also a direct correlation between miR-875-5p and E-cadherin expressions in clinical samples. MiR-875-5p promoted radiosensitivity of PCa cells by EGFR targeting [44]. E-cadherin downregulation is 
Table 1 All of the miRNAs which have been reported to regulate the protein kinases in bladder and prostate cancers

\begin{tabular}{|c|c|c|c|c|c|c|c|}
\hline Gene & Target & Cancer & Sample & Results & Country & Year & Study \\
\hline \multicolumn{8}{|c|}{ Class / receptors of tyrosine kinases } \\
\hline miR-133a/b & EGFR & Bladder & 2 cell lines & $\begin{array}{l}\text { The miR133a and miR-133b reduced tumor growth, cell } \\
\text { proliferation, and migration }\end{array}$ & China & 2012 & Zhou [39] \\
\hline miR-135a & EGFR & Prostate & $\begin{array}{l}141 \text { patients } \\
2 \text { cell lines }\end{array}$ & MiR-135a suppressed cell proliferation and migration & China & 2016 & $\mathrm{Xu}[40]$ \\
\hline $\operatorname{miR}-875-5 p$ & EGFR & Prostate & 2 cell lines & The miR-875-5p promoted radiosensitivity & Italy & 2017 & Bezawy [44] \\
\hline miR-200a & EGFR & Bladder & 3 cell lines & $\begin{array}{l}\text { MiR-200a downregulation promoted of EGFR translation } \\
\text { and enhancement of anchorage-independent tumor } \\
\text { growth }\end{array}$ & USA & 2017 & Huang [64] \\
\hline miR-133a/b & EGFR & Prostate & 2 cell lines & $\begin{array}{l}\text { MiR-133 functions as a potent tumor suppressor agent, } \\
\text { especially in androgen-independent PCa }\end{array}$ & China & 2012 & Tao [65] \\
\hline miR-4319 & Her-2 & Prostate & $\begin{array}{l}40 \text { patients } \\
2 \text { cell lines }\end{array}$ & Suppressed growth and chemoresistance & USA & 2018 & $\operatorname{Lin}[69]$ \\
\hline $\operatorname{miR}-331-3 p$ & Her-2 & Prostate & 1 cell line & MiR-331-3p was associated with PCa progression & Australia & 2011 & Epis [73] \\
\hline $\operatorname{miR}-148 a-3 p$ & ERBB3 & Bladder & $\begin{array}{l}59 \text { patients } \\
5 \text { cell lines }\end{array}$ & Suppressed EMT & China & 2016 & Wang [75] \\
\hline \multicolumn{8}{|c|}{ Class V, VII, and VIII receptors of tyrosine kinases } \\
\hline miR-99a & FGFR3 & Prostate & 2 cell lines & Inhibited PCa cell growth, invasion, and migration & China & 2014 & Wu [79] \\
\hline miR-100 & FGFR3 & Bladder & 4 cell lines & $\begin{array}{l}\text { Hypoxia increased viability of tumor cells under stressful } \\
\text { conditions through miR-100 suppression }\end{array}$ & UK & 2013 & Blick [84] \\
\hline miR-1-3p & TrkB & Bladder & $\begin{array}{l}38 \text { patients } \\
5 \text { cell lines }\end{array}$ & Inhibited the progression and invasion of $\mathrm{BCa}$ & China & 2018 & Gao $[86]$ \\
\hline $\operatorname{miR}-34 \mathrm{C}$ & MET & Prostate & $\begin{array}{l}47 \text { patients } \\
6 \text { cell lines }\end{array}$ & $\begin{array}{l}\text { There was an inverse correlation between MET and miR- } \\
34 \text { c expression levels }\end{array}$ & Sweden & 2013 & Hagman [95] \\
\hline miR-323a & c-Met & Bladder & $\begin{array}{l}20 \text { patients } \\
5 \text { cell lines }\end{array}$ & Induced apoptosis & China & 2019 & Qiu [99] \\
\hline miR-409-3p & c-Met & Bladder & $\begin{array}{l}10 \text { patients } \\
5 \text { cell lines }\end{array}$ & Inhibited BCa migration and invasion & China & 2013 & $\mathrm{Xu}[100]$ \\
\hline $\operatorname{miR}-23 b / 27 b$ & EGFR, c-MET & Bladder & $\begin{array}{l}58 \text { patients } \\
2 \text { cell lines }\end{array}$ & Suppressed proliferation and migration of BCa cells & Japan & 2014 & Chiyomaru [101] \\
\hline miR-101 & c-Met & Bladder & $\begin{array}{l}10 \text { patients } \\
2 \text { cell lines }\end{array}$ & Repressed BCa invasion & China & 2013 & $\mathrm{Hu}[106]$ \\
\hline miR-323a-3p & MET & Bladder & $\begin{array}{l}9 \text { patients } \\
4 \text { cell lines }\end{array}$ & Inhibited invasion and migration of BCa cell lines & China & 2017 & Li [107] \\
\hline miR-1 & c-Met & Prostate & 3 cell lines & Repressed the proliferation & China & 2019 & Gao $[108]$ \\
\hline \multicolumn{8}{|c|}{ Class II and X receptors of tyrosine kinases } \\
\hline miR-139 & IGF1R, AXL & Prostate & $\begin{array}{l}585 \text { patients } \\
3 \text { cell lines }\end{array}$ & Inhibited PCa cell migration, proliferation, and cell cycle & Canada & 2019 & Nam [113] \\
\hline miR-145 & IGFIR & Bladder & 3 cell lines & Tumor suppressor & China & 2014 & Zhu [114] \\
\hline Let-7a1 & IGF1R & Prostate & 1 cell line & $\begin{array}{l}\text { Suppressed prostate tumor cell proliferation, and triggers } \\
\text { cell cycle arrest and apoptosis }\end{array}$ & China & 2013 & Wang [118] \\
\hline \multicolumn{8}{|c|}{ Non-receptor tyrosine kinases } \\
\hline $\operatorname{miR}-4723$ & $\mathrm{ABL}$ & Prostate & $\begin{array}{l}57 \text { patients } \\
2 \text { cell lines }\end{array}$ & $\begin{array}{l}\text { Inhibited tumor cell proliferation and invasion and } \\
\text { induced apoptosis }\end{array}$ & USA & 2013 & Arora [121] \\
\hline miR-20a & $\mathrm{ABL} 2$ & Prostate & $\begin{array}{l}30 \text { patients } \\
5 \text { cell lines }\end{array}$ & Inhibited migration and invasion of PCa cells & China & 2014 & Qiang [126] \\
\hline miR-3607 & SRC & Prostate & $\begin{array}{l}100 \text { patients } \\
5 \text { cell lines }\end{array}$ & Suppressed the tumorigenicity & USA & 2014 & Saini $[130]$ \\
\hline miR-1 & SRC & Prostate & $\begin{array}{l}139 \text { patients } \\
2 \text { cell lines }\end{array}$ & $\begin{array}{l}\text { There was an inverse association between miR-1 and SRC } \\
\text { expression levels }\end{array}$ & Taiwan/USA & 2015 & Liu [137] \\
\hline miR-124 & SRC & Prostate & 4 cell lines & $\begin{array}{l}\text { Inhibited PCa cell proliferation, increased sensitivity to } \\
\text { enzalutamide, and triggered apoptosis }\end{array}$ & USA & 2015 & Shi $[140]$ \\
\hline miR-1178-3p & SRC & Bladder & $\begin{array}{l}82 \text { patients } \\
3 \text { cell lines }\end{array}$ & $\begin{array}{l}\text { The circFNDC3B upregulation suppressed BCa growth } \\
\text { and metastasis via miR-1178-3p sponging }\end{array}$ & China & 2018 & Liu $[143]$ \\
\hline miR-199a & YES1 & Prostate & $\begin{array}{l}74 \text { patients } \\
1 \text { cell line }\end{array}$ & Increased chemosensitivity and apoptotic cell death & China & 2017 & Chen [146] \\
\hline
\end{tabular}


Table 1 (continued)

\begin{tabular}{|c|c|c|c|c|c|c|c|}
\hline Gene & Target & Cancer & Sample & Results & Country & Year & Study \\
\hline miR-631 & ZAP70 & Prostate & $\begin{array}{l}43 \text { patients } \\
6 \text { cell lines }\end{array}$ & $\begin{array}{l}\text { Suppressed invasion and migration of prostate tumor } \\
\text { cells }\end{array}$ & China & 2016 & $\mathrm{Fu}[150]$ \\
\hline $\operatorname{miR}-214$ & PTK6 & Prostate & 5 cell lines & Reduced cell proliferation and viability in PCa & USA & 2019 & Cagle [154] \\
\hline \multicolumn{8}{|c|}{ Serine threonine kinases } \\
\hline $\operatorname{miR}-27 a$ & MAP2K4 & Prostate & $\begin{array}{l}17 \text { patients } \\
5 \text { cell lines }\end{array}$ & Tumor suppressor & China & 2016 & Wan [157] \\
\hline miR-136 & MAP2K4 & Prostate & $\begin{array}{l}27 \text { patients } \\
5 \text { cell lines }\end{array}$ & Suppressed proliferation and invasion of PCa cells & China & 2018 & Zhu [158] \\
\hline miR-1826 & MEK1 & Bladder & $\begin{array}{l}19 \text { patients } \\
4 \text { cell lines }\end{array}$ & $\begin{array}{l}\text { Inhibited cancer cell viability and invasion, and induced } \\
\text { apoptosis }\end{array}$ & USA & 2012 & Hirata [162] \\
\hline miR-30e & MAPK & Prostate & $\begin{array}{l}57 \text { patients } \\
2 \text { cell lines }\end{array}$ & Inhibited PCa cell invasion and migration & China & 2018 & Zheng [170] \\
\hline
\end{tabular}

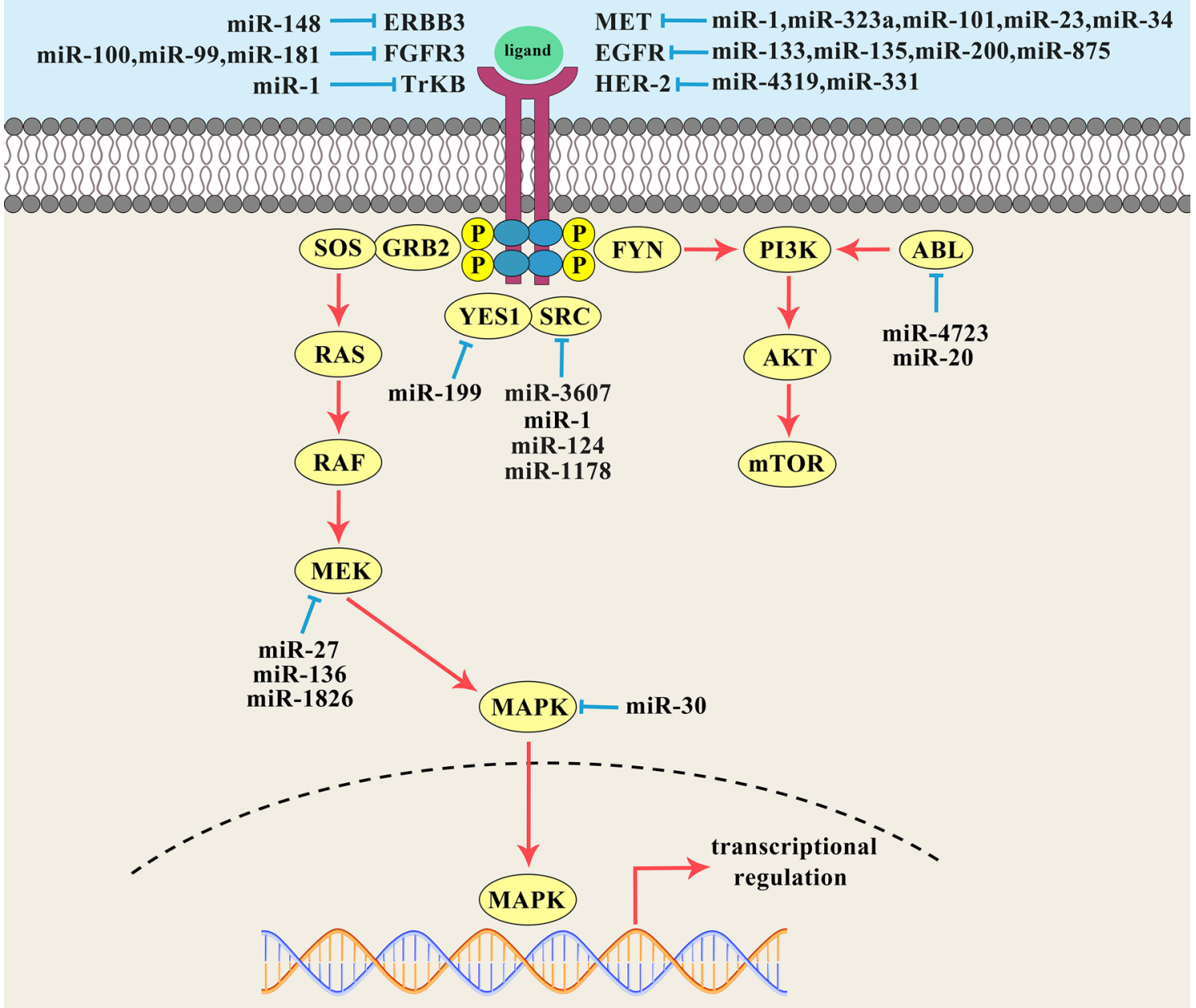

Fig. 1 All of the miRNAs-protein kinases interactions that are involved in prostate and bladder tumor progressions 
crucial for increased tumor cell motility and loss of tissue integrity during EMT process in which non-motile epithelial cells acquire mesenchymal feature. Many transcriptional repressors such as TWIST1, SNAIL1, and ZEB2/SIP1 regulate E-cadherin expression through binding to the E-box promoter sequences $[45,46]$. There were significant associations between miR-200, E-cadherin, and anti-EGFR sensitivity. MiR-200 upregulated the E-cadherin and increased sensitivity to EGFR inhibitors, whereas downregulated the ZEB-1 and ZEB-2 and suppressed cell motility [47]. EGFR activation has been reported as one of the pivotal reasons of chemoresistance [48, 49]. Targeting the EGFR signaling pathway using monoclonal antibodies to inhibit the receptor dimerization or small molecule tyrosine kinase inhibitors (TKIs) is common therapeutic strategies in EGFR-mutated cancers $[50,51]$. Ras signaling pathway upregulates the EGFR ligands which constitutes an autocrine EGFR activation loop to promote cancer progression $[52,53]$. The polycomb repressive complexes PRC1 and PRC2 are wellestablished regulators of gene expression that function in chromatin remodeling and epigenetic gene silencing in the early developmental stages [54]. The expression of Snail/Suz12 is regulated by EGFR pathways in Rasmutated PCa cells. MiR-203 had also a key role in SUZ12 regulation in PCa cells. Moreover, Snail/Suz12 axis regulated the expression of $m i R-203 a$ via a mutually inhibitory feed-forward loop in an EGF-dependent manner. EGFR signaling pathway upregulated Snail/PRCs, while suppressed the miR-203a [55]. EGFR serves as an upstream regulator of TWIST1 that is a transcription factor involved in high-grade PCa [56]. There was an association between EGFR and STAT3 to facilitate EMT process in breast cancer cells through TWIST1 upregulation [56]. It has been reported that the EGFR promoted PCa growth and bone metastasis through TWIST1 induction and miR-1 suppression. There was also an inverse correlation between TWIST1 and miR-1 expression in clinical samples [57]. X-linked inhibitor of apoptosis protein (XIAP) belongs to the inhibitors of apoptosis (IAP) family of proteins which directly suppresses apoptotic pathways. XIAP upregulation is involved in radio-chemoresistance $[58,59]$. However, XIAP downregulation renders the tumor cells vulnerable toward chemotherapeutic-related apoptosis [60, 61]. XIAP enhances the colorectal cancer growth via induction of E2F1 transcriptional activity [62]. EGFR-overexpressing tumors are more responsive to the anti-IAPs antagonists indicating a possible association between XIAP and EGFR in tumor cells [63]. XIAP suppressed the expression of Rac1 by PP2A activation. The activated PP2A inhibited MAPKK/MAPK axis and c-Jun which resulted in miR-200a downregulation. Since miR-200a suppresses EGFR expression, XIAP-related
miR-200a downregulation leads to the promotion of EGFR translation and increased anchorage-independent growth in bladder tumor cells [64]. MiR-133a/b significantly suppressed the proliferation, migration, and invasion of PCa cell lines through EGFR inhibition. MiR-133 functions as a potent tumor suppressor, especially in androgen-independent PCa. MMP-2 as an effector of EGFR pathway which is regulated through GSK3 $\beta$ / snail/E-cadherin axis was also downregulated following the miR-133a/b transfection [65]. ETS variant gene 6 (ETV6) is a member of the E26 transformation-specific family. Deletion of ETV6 has been frequently reported in PCa $[66,67]$. ETV6 is a tumor suppressor that represses cell proliferation and migration in $\mathrm{PCa}$. It was also observed that the EGFR induced miR-96 while inhibited ETV6 during PCa progression [68]. ERBB2 is also a class I receptor tyrosine kinase. MiR-4319 suppressed growth and chemoresistance in PCa cells through ERBB2 targeting. There were significant reduced levels of $m i R-4319$ in PCa specimens compared with normal margins which was associated with poor prognosis and survival. MiR4319 also upregulated the BCL-2 and CASP9 [69]. HuR belongs to the RNA-binding proteins (RBPs) involved in various physiological processes such as cell proliferation and stress responses [70]. Upregulation of $\mathrm{HuR}$ and/or its cytoplasmic aggregation has been reported in $\mathrm{PCa}[71$, 72]. The $3^{\prime}-U T R$ of ERBB2 is a specific site for the HuR binding in PCa cells that enhances ERBB2 levels through counteracting the repression of ERBB2 through miR331-3p. The concomitant upregulated HuR and downregulated $m i R-331-3 p$ were associated with PCa progression through increased ERBB2 levels [73]. ERBB3 as a transmembrane receptor belongs to the EGFR family that promotes cellular proliferation, survival, and migration [21]. Interaction of ERBB3 and p85 triggers the PI3K recruitment and activation [74]. ERBB3 downregulation suppressed EMT in UM-UC-3 and T24 bladder cancer cell lines through regulation of AKT2/Snail pathway. There were significant $E R B B 3$ upregulation and $m i R-148 a-3 p$ downregulation in $\mathrm{BCa}$ tissues compared with normal margins. MiR-148a-3p directly targeted the ERBB3, DNMT1, and AKT2 [75].

\section{Class V, VII, and VIII receptors of tyrosine kinases}

Fibroblast growth factor receptor 3 (FGFR3) is a member of the trans-membrane tyrosine kinase family of receptors that functions as a key regulator of multiple cellular and biological processes such as cell growth, differentiation, apoptosis, migration, and tumor progression [76, 77]. Increased levels of circ0068871 were observed in $\mathrm{BCa}$ tissues compared with normal margins which were correlated with N-stage and T-stage. Circ0068871 enhanced $\mathrm{BCa}$ progression via FGFR3 upregulation and 
STAT3 activation following the miR-181a-5p sponging [78]. MiR-99a also inhibited PCa cell growth, tumorigenesis, invasion, and migration through FGFR3 downregulation [79]. Non-muscle-invasive $\mathrm{BCa}$ is characterized by upregulation and gain-of-function mutations of various oncogenes including FGFR3, H-RAS, and PI3K [80, 81]. FGFR activation triggers downstream pathways such as ERK/MAPK and PI3K [82]. Hypoxia-inducible factor (HIF) is a heterodimer transcription factor (HIF-1a or HIF-2a) that mediates the biological effect of hypoxia through binding to the hypoxia-responsive elements (HREs) in promoter sequence of target genes such as VEGF and LOX [83]. It has been reported that the hypoxia increased FGFR3 expression in NMIBCa cell lines. FGFR3 knockdown reduced the phosphorylation and activation of protein kinase B and MAPK signaling. Hypoxia increased viability of tumor cells under stressful conditions through miR-100 suppression that resulted in FGFR3 upregulation in $\mathrm{BCa}$ [84]. Brain-derived neurotrophic factor (BDNF) belongs to the neurotrophin family of growth factors that bind with tropomyosin-related kinase $\mathrm{B}$ (TrkB) to regulate the survival, differentiation, and maturation of neurons and synapses [85]. MiR-1-3p downregulation was observed in UM-UC-3 BCa cell line. It also inhibited the progression and invasion of $\mathrm{BCa}$ via modulation of BDNF/TrkB axis [86].

Met proto-oncogene (MET) belongs to the receptor tyrosine kinase family involved in tumor cells invasion and migration $[87,88]$. Activation of c-MET initiates various signaling cascades including PI3K-AKT, STAT, RAS, and WNT [89-92]. It is upregulated in metastatic tumors as well as castration-resistant PCa [93, 94]. An inverse correlation was reported between the MET and miR-34c expression levels in PCa cells [95]. c-MET over expression in $\mathrm{BCa}$ is associated with malignant transformation of normal cells, increased cell proliferation, angiogenesis, and poor prognosis [96, 97]. Activated c-Met promotes growth and invasion of tumor cells and endothelial cells, while inhibits apoptosis [98]. There were significant $m i R-323 a$ downregulations in BCa tissues and cell lines. MiR-323a induced apoptosis of $\mathrm{BCa}$ cells through c-MET inhibition [99]. MiR-409-3p downregulation was also observed in $\mathrm{BCa}$ tissues and cell lines. MiR-409-3p inhibited BCa migration and invasion through suppressing c-MET [100]. MiR-23b and $m i R-27 b$ also suppressed proliferation and migration of BCa cells through EGFR and c-MET targeting [101]. MiR-101 as an inhibitor of cell migration and invasion is significantly downregulated in multiple malignancies such as lung, colon, and prostate cancers [102-104]. Aberrant expression and activation of the HGF/c-MET axis were associated with EMT process and BCa progression and aggressiveness [105]. Significant miR-101 downregulation was reported in $\mathrm{BCa}$ tissues and cell lines compared with controls. MiR-101 suppressed the T24 cells invasion, whereas c-MET upregulation increased T24 cells invasion. Therefore, it was concluded that the miR-101 repressed $\mathrm{BCa}$ invasion through c-Met targeting [106]. It has been observed that the miR-433 suppressed EMT through regulating AKT/GSK-3 $\beta /$ Snail signaling pathway in BCa cells in which CREB1 and c-Met were downregulated by $m i R$ 433. There was significant $m i R-433$ downregulation in tumor cells compared with normal margins. MiR433-induced c-Met suppression inhibited the AKT and induced GSK-3 $\beta$, which were contributed to the Snail nuclear accumulation and elevated E-cadherin expression. CREB1 downregulation inhibited AKT/GSK-3 $\beta /$ Snail signaling pathway in BCa cells [96]. MiR-323a-3p significantly inhibited the EMT progression of $\mathrm{BCa}$ cells through regulating MET/SMAD3/SNAIL signaling. MiR-323a-3p also inhibited invasion and migration of $\mathrm{BCa}$ cell lines through inhibiting MET to regulate AKT/GSK-3 $\beta /$ SNAIL axis [107]. MiR-1 was downregulated in PCa cells compared with normal margins. It functioned as a tumor suppressor that repressed the proliferation of prostate tumor cells through targeting the c-MET/AKT/mTOR axis [108].

\section{Class II and X receptors of tyrosine kinases}

IGF1R is a tyrosine kinase receptor involved in important biological and physiological processes such as cellular differentiation, proliferation, migration, and tissue homeostasis $[109,110]$. IGF1R activation has been identified to be correlated with poorer prognosis of PCa [110]. AXL is a trans-membrane receptor tyrosine kinase which constitutes the TAM family of receptor tyrosine kinases along with TYRO3 and MER [111]. AXL regulates PCa invasion and proliferation [112]. It has been reported that the miR-139 suppressed the AXL and IGF1R in PCa cells. The patients without tumor recurrence had higher expression levels of miR-139 compared with metastatic cases. There were significant associations between $m i R$ 139 downregulation and poor prognostic indicators such as high tumor stage/grade, lymph node involvement, and recurrence. MiR-139 inhibited PCa cell migration, proliferation, and cell cycle via targeting AXL and IGF1R which leads to downstream effects on the PI3K/AKT axis and cyclin D1 downregulation [113]. MiR-145 was introduced as a tumor suppressor via IGF-IR suppression in bladder tumor cells [114]. IGF1R is upregulated in metastatic and hormone-resistant PCa [115-117]. Let-7a1 suppressed prostate tumor cell proliferation, while triggered cell cycle arrest and apoptosis via IGF1R, c-FOS, and $E L K 1$ inhibition [118]. 


\section{Non-receptor tyrosine kinases}

The Abelson (ABL) family of non-receptor protein tyrosine kinases is implicated in cell differentiation, proliferation, adhesion, and motility [119]. Integrin alpha3 (ITGA3) is a cell adhesion molecule involved in tumor cell proliferation and migration [120]. It has been reported that there was a significant decreased levels of $m i R-4723$ expressions in PCa tissues which was associated with poorer prognosis. $M i R-4723$ inhibited tumor cell proliferation and invasion and induced apoptosis through $A B L$ kinases and ITGA3 targeting [121]. ABL1 and ABL2 are distinct members of ABL family which are ubiquitously expressed and function as key regulators of multiple oncogenic signaling cascades promoting cell proliferation, survival, adhesion, and migration through the actin remodeling [122]. ABL kinases are involved in the actin cytoskeleton reorganization mediated by adaptor proteins such as CRKL and CRK [123]. ABL2 inhibits RhoA by depolymerization of F-actin which results in cytoskeleton collapse and cell migration suppression [124, 125]. MiR-20a upregulation was observed in PCa tissues compared with normal margin which was correlated with poorer prognoses. The inhibitory function of $m i R-20 a$ on migration and invasion of $\mathrm{PCa}$ cell lines was achieved through $A B L 2$ targeting [126]. SRC kinase family is a family of non-receptor tyrosine kinases that are implicated in key signaling pathways responsible for cell growth, differentiation, migration, and apoptosis [127, 128]. Overexpression of SRC kinase is associated with higher risk of tumor metastasis and poor prognosis in PCa [127, 129]. It has been revealed that there were significant correlations between miR-3607 downregulation, increased tumor growth, PSA levels, and lower survival in PCa. MiR-3607 also significantly suppressed the tumorigenicity of cancer cells through SRC kinases targeting [130]. Hormone ablation therapy is used to temporarily manage metastatic PCa symptoms and tumor growth; however, tumor cells will finally become resistant to hormone therapy. Reconstitution of androgen receptor (AR)-mediated signaling is a core process that leads to castration-resistant prostate cancer (CRPC) [131, 132]. SRC interacts with multiple receptor families and is especially activated in downstream of receptor tyrosine kinases [133]. SRC is considered as an upstream signaling molecule involved in the survival of PCa cells in AR deprivation conditions [133-136]. MiR-1 was involved in inhibition of the in vivo bone metastasis. AR upregulated the $m i R-1$ through binding to the miR-1-2 regulatory region. There was an inverse association between $m i R-1$ and $S R C$ expression levels. Low canonical AR signature also downregulated and upregulated the $m i R-1$ and $S R C$, respectively, in PCa [137]. Enhancer of zeste homolog 2 (EZH2) is a histone-lysine N-methyltransferase that suppresses tumor-suppressor genes [138] and induces AR during PCa progression [139]. MiR-124 inhibited PCa cell proliferation, increased sensitivity to enzalutamide, and triggered apoptotic death through $A R, E Z H 2$, and $S R C$ tyrosine kinase targeting [140]. G3BP2 belongs to the Ras-GTPase-activating protein (RasGAP) SH3 domain-binding protein (G3BP) family. G3BP2 upregulation is associated with tumor invasiveness [141]. Focal adhesion kinase (FAK) has key functions in cancer progression and invasion through interaction with steroid receptor coactivator (SRC) [142]. A significant circFNDC3B downregulation was observed in $\mathrm{BCa}$ tissues and cell lines which were correlated with high tumor stage and grade, lymph node involvement, and poor prognosis. CircFNDC3B suppressed $\mathrm{BCa}$ growth and metastasis via $m i R-1178-3 p$ sponging that downregulated the G3BP2 and inhibited the SRC/FAK phosphorylation [143]. Yamaguchi sarcoma viral homolog 1 (YES1) is a proto-oncogene tyrosine-protein kinase which belongs to the SRC family involved in tumor cell proliferation and chemoresistance [144, 145]. There was a significant lower level of miR-199a in PCa tissues compared with normal margins. MiR-199a downregulation was also characteristic of paclitaxel-resistant and aggressive $\mathrm{PCa}$ through YES1 targeting. Increased chemosensitivity and apoptotic cell death and YES1 inhibition were observed in PCa cells with miR-199a upregulation [146]. Zetaassociated protein 70 (ZAP70) is a member of the SYK tyrosine kinases which has a pivotal role for $\mathrm{T}$ cell migration and $\mathrm{T}$ cell hybridoma invasion [147, 148]. ZAP-70 expression is also correlated with increased response to the survival and migration signals in B cell chronic lymphocytic leukemia [149]. An inverse association was reported between ZAP70 and miR-631 in PCa tissues and cell lines. MiR-631 suppressed invasion and migration of prostate tumor cells via ZAP70 inhibition [150]. Protein tyrosine kinase 6 (PTK6) is a nonreceptor tyrosine kinase involved in modulation of cell growth and differentiation [151-153]. PTK6 induces EMT through AKT41 activation. MiR-214 suppressed growth and migration of PCa cell lines through PTK6 targeting. Ibrutinib (IBT) is a chemotherapeutic medication that permanently binds and irreversibly inhibits Bruton tyrosine kinase (BTK). It is conventionally used for the treatment of liquid malignancies such as mantle cell lymphoma and chronic lymphocytic leukemia. The results demonstrated that inhibiting PTK6 using $m i R$ 214 alone or in concomitant administration of $m i R-214$ and IBT reduced cell proliferation and viability in $\mathrm{PCa}$ [154]. 


\section{Serine threonine kinases}

MAP2K4 belongs to the MAPK signaling pathway involved in regulation of cell proliferation, cell cycle, apoptosis, tumor progression, and distant metastasis $[155,156]$. MAPK family members serve as an integration point for the various biochemical signals. $M i R-27 a$ exerted its tumor-suppressive function through $M A P 2 K 4$ targeting and inhibiting in prostate tumors. There were reduced levels of $m i R-27 a$ expressions in $\mathrm{PCa}$ cells. Moreover, PI3K signaling pathway suppressed the $m i R$ $27 a$ expression in castration-resistant $\mathrm{PCa}$ [157]. MiR136 downregulation was observed in $\mathrm{PCa}$ tissues and cell lines. It also suppressed proliferation and invasion of PCa cells through directly targeting MAP2K4 [158]. Ras/Raf/MAPK pathway is regarded as the most characterized signaling pathway among all MAPK signal transduction pathways. Following the activation of Ras, the protein kinase activity of Raf is triggered, and MEK (MEK1 and MEK2) is activated [159]. Activation of the Ras pathway was closely associated with WNT to drive bladder tumor progression [160]. Different growth factors such as VEGFC have been reported to be associated with the elevated activity of Ras/Raf/MEK/ERK pathway. CTNNB1 is a core component of the WNT pathway in $\mathrm{BCa}$ [161]. There were inverse correlations between $m i R$ 1826, MEK1, VEGFC, and CTNNB1 expressions which are the direct targets of $m i R-1826$. MiR-1826 also suppressed the survivin expression in transfected cells. BCa cells had significant downregulated miR-1826 levels compared with normal cells. MiR-1826 inhibited cancer cell viability and invasion and induced apoptosis through $M E K 1, V E G F C$, and CTNNB1 suppressing [162]. A variety of antioxidants including curcumin, resveratrol, and isoflavone have promising efficacy in suppressing the progression and metastasis of different tumors [163]. Resveratrol is a polyphenol found in red grapes, peanuts, and berries [164, 165]. Resveratrol exerts its anticancer activity through upregulating estrogen receptor-b and suppressing the phosphorylation of IGF-1 and ERK1/2 [166]. It has been shown that the resveratrol inhibited PCa cells viability and migration through AKT-mediated $m i R-21$ downregulation. Therefore, AKT/miR-21 pathway is an important target of resveratrol that mediates its anticancer activity in highly aggressive PCa cells. Phosphorylation of AKT and upregulation of $m i R-21$ targeted the PDCD4 which inhibited the eukaryotic initiation factor 4A (eIF4A). PDCD4 also suppressed AP1-dependent transcriptional activity via c-Jun inhibition that prevented its growth-stimulating function [167]. MiR-30e drives NF-kB-mediated PCa proliferation and growth through inhibition of IkB $\alpha$ [168]. Blockade of M3 muscarinic acetylcholine receptor (CHRM3) inhibits the castration-resistant growth of $\mathrm{PCa}$ cells and increases their sensitivity to androgen deprivation through CaM/ CaMKK-mediated phosphorylation of AKT [169]. There were reduced and increased levels of $m i R-30 e$ and CHRM3, respectively, in PCa tissues compared with normal margins. MiR-30e inhibited PCa cell invasion and migration via CHRM3 downregulation and inhibition of MAPK signaling pathway [170].

\section{Conclusions}

For the first time, this review highlights the miRNAs as the pivotal regulators of protein kinases in bladder and prostate cancers. It was observed that the class VIII receptors of tyrosine kinases and non-receptor tyrosine kinases were the most frequent targets for the miRNAs in bladder and prostate cancers, respectively. As the miRNAs are more stable and noninvasive markers compared with mRNAs, they can be efficiently introduced as kinase-specific noninvasive markers for the early detection of bladder and prostate cancers.

\section{Abbreviations}

ABL: Abelson; AR: Androgen receptor; BCa: Bladder cancer; BDNF: Brainderived neurotrophic factor; CRPC: Castration-resistant prostate cancer; ZEB1: E-box binding homeobox 1; ETV6: ETS variant gene 6; EZH2: Enhancer of zeste homolog 2; elF4A: Eukaryotic initiation factor 4A; FGFR3: Fibroblast growth factor receptor 3; FAK: Focal adhesion kinase; HIF: Hypoxia-inducible factor; HREs: Hypoxia-responsive elements; IBT: Ibrutinib; IAP: Inhibitors of apoptosis; ITGA3: Integrin alpha3; CHRM3: M3 muscarinic acetylcholine receptor; miRNAs: MicroRNAs; MIBC: Muscle-invasive bladder cancer; NMIBC: Non-muscleinvasive bladder cancer; PCa: Prostate cancer; PTK6: Protein tyrosine kinase 6; G3BP: Ras-GTPase-activating protein SH3 domain-binding protein; SRC: Steroid receptor coactivator; TCC: Transitional cell carcinoma; TrkB: Tropomyosin-related kinase B; TKIs: Tyrosine kinase inhibitors; TKs: Tyrosine kinases; YES1: Yamaguchi sarcoma viral homolog 1

\section{Acknowledgements}

Not applicable.

\section{Authors' contributions}

MZ, ASZ, and MMojarrad were involved in search strategy and drafting. MMoghbeli supervised the project and revised and edited the manuscript. All authors read and approved the final manuscript.

\section{Funding}

Not applicable.

\section{Availability of data and materials}

The datasets used and/or analyzed during the current study are available from the corresponding author on reasonable request.

\section{Declarations}

Ethics approval and consent to participate

Not applicable.

Consent for publication

Not applicable.

Competing interests

The authors declare that they have no competing interests. 


\section{Author details}

'Department of Anesthesiology, Faculty of Medicine, Birjand University of Medical Sciences, Birjand, Iran. ${ }^{2}$ Student Research Committee, Faculty of Medicine, Mashhad University of Medical Sciences, Mashhad, Iran. ${ }^{3}$ Department of Medical Genetics and Molecular Medicine, School of Medicine, Mashhad University of Medical Sciences, Mashhad, Iran.

Received: 30 March 2021 Accepted: 30 July 2021

Published online: 08 September 2021

\section{References}

1. Kinoshita Y et al (2004) Double primary cancers of the prostate and bladder: a literature review. Clin Prostate Cancer 3(2):83-86

2. Bray F et al (2018) Global cancer statistics 2018: GLOBOCAN estimates of incidence and mortality worldwide for 36 cancers in 185 countries. CA Cancer J Clin 68(6):394-424

3. Babjuk M, Oosterlinck W, Sylvester R, Kaasinen E, Böhle A, PalouRedorta J, Rouprêt M (2011) EAU guidelines on non-muscle-invasive urothelial carcinoma of the bladder, the 2011 update. European Urol. 59(6):997-1008

4. Siegel RL, Miller KD, Jemal A (2018) Cancer statistics, 2018. CA Cancer J Clin 68(1):7-30

5. Czerniak B, Dinney C, McConkey (2016) Origins of bladder cancer. Annu Rev Pathol. 11:149-74

6. Bellmunt J, Petrylak DP (2012) New therapeutic challenges in advanced bladder cancer. In: Seminars in oncology. Elsevier

7. Burger M et al (2013) Epidemiology and risk factors of urothelial bladder cancer. Eur Urol. 63(2):234-241

8. Cheung G et al (2013) Recent advances in the diagnosis and treatment of bladder cancer. BMC Med 11(1):13

9. Martyn-Hemphill C et al (2013) Recent advances in diagnosis and treatment of transitional cell carcinoma of the bladder. Int J Surg 11(9):749-752

10. Dovedi SJ, Davies BRJC, Reviews M (2009) Emerging targeted therapies for bladder cancer: a disease waiting for a drug. Cancer Metastasis Rev 28(3-4):355

11. Hartge $P$ et al (1990) Unexplained excess risk of bladder cancer in men. J Natl Cancer Inst 82(20):1636-1640

12. Mojarrad M, Moghbeli M (2020) Genetic and molecular biology of bladder cancer among Iranian patients. Mol Genet Genomic Med 8(6):e1233

13. Jemal A et al (2009) Cancer statistics, 2009. CA Cancer J Clin 59(4):225-249

14. Steele CB et al (2017) Prostate cancer survival in the United States by race and stage (2001-2009): findings from the CONCORD-2 study. Cancer 123:5160-5177

15. Shavers VL, Underwood W, Moser RP (2009) Race/ethnicity and the perception of the risk of developing prostate cancer. Am J Prev Med. 37(1):64-67

16. Ghayour-Mobarhan M, Ferns GA, Moghbeli M (2020) Genetic and molecular determinants of prostate cancer among Iranian patients: An update. Crit Rev Clin Lab Sci 57(1):37-53

17. Manning $\mathrm{G}$ et al (2002) The protein kinase complement of the human genome. Science. 298(5600):1912-34

18. Hubbard MJ, Cohen P (1993) On target with a new mechanism for the regulation of protein phosphorylation. Trends Biochem Sci. 18(5):172-177

19. Nattel S et al (2007) Arrhythmogenic ion-channel remodeling in the heart: heart failure, myocardial infarction, and atrial fibrillation. Physiol Rev. 87(2):425-456

20. Moghbeli M et al (2013) Association of PYGO2 and EGFR in esophageal squamous cell carcinoma. Med Oncol 30(2):516

21. Moghbeli M et al (2019) ErbB1 and ErbB3 co-over expression as a prognostic factor in gastric cancer. Biol Res 52(1):2

22. Zangouei AS et al (2020) Role of tyrosine kinases in bladder cancer progression: an overview. Cell Commun Signal 18(1):127

23. Krause DS, Van Etten RA (2005) Tyrosine kinases as targets for cancer therapy. New England J Med. 353(2):172-187
24. Bartel DP (2004) MicroRNAs: genomics, biogenesis, mechanism, and function. Cell 116(2):281-297

25. Shi Z et al (2017) Exploring the key genes and pathways of osteosarcoma with pulmonary metastasis using a gene expression microarray. Molec Med Rep. 16(5):7423-7431

26. Nishikawa R et al (2015) MicroRNA-205 inhibits cancer cell migration and invasion via modulation of centromere protein $\mathrm{F}$ regulating pathways in prostate cancer. Int J Urol 22(9):867-877

27. Gandellini P et al (2014) miRNAs in tumor radiation response: bystanders or participants? Trends Mol Med 20(9):529-539

28. Leonetti A et al (2019) MicroRNAs as a drug resistance mechanism to targeted therapies in EGFR-mutated NSCLC: Current implications and future directions. Drug Resist Updat 42:1-11

29. Ohno S et al (2013) Systemically injected exosomes targeted to EGFR deliver antitumor microRNA to breast cancer cells. Mol Ther 21(1):185-191

30. Yokoi T, Nakajima M (2013) microRNAs as mediators of drug toxicity. Annu Rev Pharmacol Toxicol 53:377-400

31. Zanger UM, Schwab M (2013) Cytochrome P450 enzymes in drug metabolism: regulation of gene expression, enzyme activities, and impact of genetic variation. Pharmacol Ther 138(1):103-141

32. Vanacore D et al (2017) Micrornas in prostate cancer: an overview. Oncotarget 8(30):50240

33. Braicu C et al (2015) Clinical and pathological implications of miRNA in bladder cancer. Int J Nanomedicine 10:791

34. Brighenti M (2015) MicroRNA and MET in lung cancer. Ann Transl Med 3(5):68

35. Gomez GG et al (2013) Therapeutic resistance in cancer: microRNA regulation of EGFR signaling networks. Cancer Biol Med 10(4):192-205

36. Carpenter G, Cohen S (1990) Epidermal growth factor. J Biol Chem. 265(14):7709-7712

37. Sarkar S et al (2010) ZD6474, a dual tyrosine kinase inhibitor of EGFR and VEGFR-2, inhibits MAPK/ERK and AKT/PI3-K and induces apoptosis in breast cancer cells. Cancer Biol Ther 9(8):592-603

38. Guo X et al (2011) AKT activation by Pdcd4 knockdown up-regulates cyclin D1 expression and promotes cell proliferation. Genes Cancer 2(8):818-828

39. Zhou Y et al (2013) MicroRNA-133 inhibits cell proliferation, migration and invasion by targeting epidermal growth factor receptor and its downstream effector proteins in bladder cancer. Scand J Urol 47(5):423-432

40. Xu B et al (2016) hsa-miR-135a-1 inhibits prostate cancer cell growth and migration by targeting EGFR. Tumour Biol 37(10):14141-14151

41. Lu Y et al (2016) The long non-coding RNA NEAT1 regulates epithelial to mesenchymal transition and radioresistance in through miR-204/ZEB axis in nasopharyngeal carcinoma. Tumor Biol. 37(9):11733-11741

42. Zhang $P$ et al (2014) miR-205 acts as a tumour radiosensitizer by targeting ZEB1 and Ubc13. Nat Commun. 5(1):1-10

43. Zhang P et al (2014) ATM-mediated stabilization of ZEB1 promotes DNA damage response and radioresistance through CHK1. Nat Cell Biol. 16(9):864-875

44. El Bezawy R et al (2017) miR-875-5p counteracts epithelial-to-mesenchymal transition and enhances radiation response in prostate cancer through repression of the EGFR-ZEB1 axis. Cancer Lett. 395:53-62

45. Pettitt J (2005) The cadherin superfamily, in WormBook: the online review of $\mathrm{C}$. elegans Biology. WormBook

46. Forghanifard MM et al (2017) TWIST1 upregulates the MAGEA4 oncogene. Mol Carcinog 56(3):877-885

47. Adam L et al (2009) miR-200 expression regulates epithelial-tomesenchymal transition in bladder cancer cells and reverses resistance to epidermal growth factor receptor therapy. Clin Cancer Res 15(16):5060-5072

48. Paez JG et al (2004) EGFR mutations in lung cancer: correlation with clinical response to gefitinib therapy. Science 304(5676):1497-1500

49. Nathanson DA et al (2014) Targeted therapy resistance mediated by dynamic regulation of extrachromosomal mutant EGFR DNA. Science 343(6166):72-76

50. Matar P et al (2004) Combined epidermal growth factor receptor targeting with the tyrosine kinase inhibitor gefitinib (ZD1839) and the monoclonal antibody cetuximab (IMC-C225): superiority over singleagent receptor targeting. Clin Cancer Res 10(19):6487-6501 
51. Gelsomino F et al (2013) Epidermal growth factor receptor tyrosine kinase inhibitor treatment in patients with EGFR wild-type non-smallcell lung cancer: the never-ending story. J Clin Oncol 31(26):3291-3293

52. Schulze A et al (2004) The transcriptional response to Raf activation is almost completely dependent on mitogen-activated protein kinase kinase activity and shows a major autocrine component. Molec Biol Cell. 15(7):3450-3463

53. McCarthy SA et al (1995) Rapid induction of heparin-binding epidermal growth factor/diphtheria toxin receptor expression by Raf and Ras oncogenes. Genes Develop. 9(16):1953-1964

54. Schwartz YB, Pirrotta V (2008) Polycomb complexes and epigenetic states. Curr Opin Cell Biol. 20(3):266-273

55. Siu MK et al (2014) Loss of EGFR signaling-regulated miR-203 promotes prostate cancer bone metastasis and tyrosine kinase inhibitors resistance. Oncotarget 5(11):3770

56. Qin Q et al (2012) Normal and disease-related biological functions of Twist1 and underlying molecular mechanisms. Cell Res 22(1):90-106

57. Chang Y-S et al (2015) EGF receptor promotes prostate cancer bone metastasis by downregulating miR-1 and activating TWIST1. Cancer Res 75(15):3077-3086

58. Flanagan $L$ et al (2015) High levels of X-linked Inhibitor-of-Apoptosis Protein (XIAP) are indicative of radio chemotherapy resistance in rectal cancer. Radiat Oncol 10(1):131

59. Holcik M et al (2000) Translational upregulation of X-linked inhibitor of apoptosis (XIAP) increases resistance to radiation induced cell death. Oncogene 19(36):4174-4177

60. Hu Y et al (2003) Antisense oligonucleotides targeting XIAP induce apoptosis and enhance chemotherapeutic activity against human lung cancer cells in vitro and in vivo. Clin Cancer Res 9(7):2826-2836

61. Amantana A et al (2004) X-linked inhibitor of apoptosis protein inhibition induces apoptosis and enhances chemotherapy sensitivity in human prostate cancer cells. Mol Cancer Ther 3(6):699-707

62. Cao Z et al (2014) X-linked inhibitor of apoptosis protein (XIAP) lacking RING domain localizes to the nuclear and promotes cancer cell anchorage-independent growth by targeting the E2F1/Cyclin E axis. Oncotarget 5(16):7126

63. Lee $\mathrm{S}$ et al (2014) A novel antagonist to the inhibitors of apoptosis (IAPS) potentiates cell death in EGFR-overexpressing non-small-cell lung cancer cells. Cell Death Dis 5(10):e1477-e1477

64. Huang C et al (2017) XIAP BIR domain suppresses miR-200a expression and subsequently promotes EGFR protein translation and anchorage-independent growth of bladder cancer cell. J Hematol Oncol 10(1):6

65. Tao J et al (2012) microRNA-133 inhibits cell proliferation, migration and invasion in prostate cancer cells by targeting the epidermal growth factor receptor. Oncol Rep 27(6):1967-1975

66. Kibel AS, et al (1998) Identification of $12 p$ as a region of frequent deletion in advanced prostate cancer. Cancer Res 58(24):5652-5655

67. Taylor BS et al (2010) Integrative genomic profiling of human prostate cancer. Cancer Cell 18(1):11-22

68. Tsai Y-C et al (2017) Epidermal growth factor receptor signaling promotes metastatic prostate cancer through microRNA-96-mediated downregulation of the tumor suppressor ETV6. Cancer Lett. 384:1-8

69. Lin X, Wang YJC, Oncology T (2018) Re-expression of microRNA-4319 inhibits growth of prostate cancer via Her-2 suppression. Clin Transl Oncol 20(11):1400-1407

70. Hinman MN, Lou H (2008) Diverse molecular functions of Hu proteins. Cell Mol Life Sci. 65(20):3168-3181

71. Niesporek $S$ et al (2008) Expression of the ELAV-like protein HuR in human prostate carcinoma is an indicator of disease relapse and linked to COX-2 expression. Int J Oncol. 32(2):341-347

72. Barbisan F et al (2009) Overexpression of ELAV-like protein HuR is associated with increased COX-2 expression in atrophy, high-grade prostatic intraepithelial neoplasia, and incidental prostate cancer in cystoprostatectomies. Eur Urol. 56(1):105-112

73. Epis MR et al (2011) The RNA-binding protein HuR opposes the repression of ERBB-2 gene expression by microRNA miR-331-3p in prostate cancer cells. J Biol Chem 286(48):41442-41454

74. Hynes NE, Lane HA (2005) ERBB receptors and cancer: the complexity of targeted inhibitors. Nat Rev Cancer. 5(5):341-354
75. Wang $X$, et al (2016) miR-148a-3p represses proliferation and EMT by establishing regulatory circuits between ERBB3/AKT2/c-myc and DNMT1 in bladder cancer. Cell Death Dis 7(12):e2503

76. Mahe M, et al (2018) An FGFR 3/MYC positive feedback loop provides new opportunities for targeted therapies in bladder cancers. EMBO Mol Med 10(4):e8163

77. Katoh M (2016) Therapeutics targeting FGF signaling network in human diseases. Trends Pharmacol Sci 37(12):1081-1096

78. Mao W et al (2019) Circular RNA hsa_circ_0068871 regulates FGFR3 expression and activates STAT3 by targeting miR-181a-5p to promote bladder cancer progression. J Exp Clin Cancer Res 38(1):1-14

79. Wu D et al (2015) microRNA-99a inhibits cell poliferation, colony formation ability, migration and invasion by targeting fibroblast growth factor receptor 3 in prostate cancer. Mol Med Rep. 11(2):1469-1475

80. Pollard C, Smith SC, Theodorescu D (2010) Molecular genesis of nonmuscle-invasive urothelial carcinoma (NMIUC). Expert Rev Mol Med 12:e10

81. Castillo-Martin M et al. Molecular pathways of urothelial development and bladder tumorigenesis. In Urologic oncology: seminars and original investigations. Elsevier; 2010.

82. L'Hôte CG, Knowles MA (2005) Cell responses to FGFR3 signalling: growth, differentiation and apoptosis. Exp Cell Res. 304(2):417-431

83. Brahimi-Horn MC, Pouysségur J (2009) HIF at a glance. J Cell Sci. 122(8):1055-1057

84. Blick C et al (2013) Hypoxia regulates FGFR3 expression via HIF-1a and miR-100 and contributes to cell survival in non-muscle invasive bladder cancer. British J Cancer. 109(1):50-59

85. Long J et al (2016) MicroRNA-15a-5p suppresses cancer proliferation and division in human hepatocellular carcinoma by targeting BDNF. Tumour Biol 37(5):5821-5828

86. Gao L et al (2018) MiR-1-3p inhibits cell proliferation and invasion by regulating BDNF-TrkB signaling pathway in bladder cancer. Neoplasma 65(1):89-96

87. Birchmeier C et al (2003) Met, metastasis, motility and more. Nat Rev Mol Cell Biol 4(12):915-925

88. Trusolino L, Bertotti A, Comoglio PM (2010) MET signalling: principles and functions in development, organ regeneration and cancer. Nat Rev Mol Cell Biol. 11(12):834-848

89. O'Brien LE et al (2004) ERK and MMPs sequentially regulate distinct stages of epithelial tubule development. Dev Cell 7(1):21-32

90. Graziani A et al (1991) The tyrosine-phosphorylated hepatocyte growth factor/scatter factor receptor associates with phosphatidylinositol 3-kinase. J Biol Chem 266(33):22087-22090

91. Boccaccio C et al (1998) Induction of epithelial tubules by growth factor HGF depends on the STAT pathway. Nature 391(6664):285-288

92. Monga SP et al (2002) Hepatocyte growth factor induces Wnt-independent nuclear translocation of beta-catenin after Met-beta-catenin dissociation in hepatocytes. Cancer Res 62(7):2064-2071

93. Humphrey PA et al (1995) Hepatocyte growth factor and its receptor (c-MET) in prostatic carcinoma. Am J Pathol 147(2):386

94. Knudsen BS et al (2002) High expression of the Met receptor in prostate cancer metastasis to bone. Urology 60(6):1113-1117

95. Hagman Z et al (2013) The tumour suppressor miR-34c targets MET in prostate cancer cells. Br J Cancer 109(5):1271-1278

96. Xu X et al (2016) c-Met and CREB1 are involved in miR-433-mediated inhibition of the epithelial-mesenchymal transition in bladder cancer by regulating Akt/GSK-3 $\beta /$ Snail signaling. Cell Death Dis 7(2):e2088-e2088

97. Kim Y-W et al (2015) The c-MET network as novel prognostic marker for predicting bladder cancer patients with an increased risk of developing aggressive disease. PLoS One 10(7):e0134552

98. Cil l et al (2017) Complete response to crizotinib in a patient with adenocarcinoma of the lung cancer harboring c-MET amplification. J BUON 22(1):279

99. Qiu J et al (2019) Increased miR-323a induces bladder cancer cell apoptosis by suppressing c-Met. Kaohsiung J Med Sci 35(9):542-549

100. Xu X et al (2013) MicroRNA-409-3p inhibits migration and invasion of bladder cancer cells via targeting c-Met. Mol Cells 36(1):62-68

101. Chiyomaru T et al (2015) Dual regulation of receptor tyrosine kinase genes EGFR and c-Met by the tumor-suppressive microRNA-23b/27b cluster in bladder cancer. Int J Oncol 46(2):487-496 
102. Schee $K$ et al (2012) Clinical relevance of microRNA miR-21, miR-31, miR-92a, miR-101, miR-106a and miR-145 in colorectal cancer. BMC Cancer 12(1):505

103. Luo L et al (2012) MiR-101 and MCl-1 in non-small-cell lung cancer: expression profile and clinical significance. Med Oncol 29(3):1681-1686

104. Hao Y et al (2011) Enforced expression of miR-101 inhibits prostate cancer cell growth by modulating the COX-2 pathway in vivo. Cancer Prev Res (Phila) 4(7):1073-1083

105. Yeh C-Y et al (2011) Transcriptional activation of the Axl and PDGFR-a by c-Met through a ras-and Src-independent mechanism in human bladder cancer. BMC Cancer. 11(1):1-12

106. Hu Z et al (2013) MicroRNA-101 suppresses motility of bladder cancer cells by targeting c-Met. Biochem Biophys Res Commun 435(1):82-87

107. Li J et al (2017) MET/SMAD3/SNAIL circuit mediated by miR-323a-3p is involved in regulating epithelial-mesenchymal transition progression in bladder cancer. Cell Ceath Dis 8(8):e3010-e3010

108. Gao S et al (2019) MiR-1 inhibits prostate cancer PC3 cells proliferation through the Akt/mTOR signaling pathway by binding to c-Met. Biomed Pharmacother. 109:1406-1410

109. Heidegger I et al (2015) The insulin-like growth factor (IGF) axis as an anticancer target in prostate cancer. Cancer Lett. 367(2):113-121

110. Ozkan EE. Plasma and tissue insulin-like growth factor-I receptor (IGF-IR) as a prognostic marker for prostate cancer and anti-IGF-IR agents as novel therapeutic strategy for refractory cases: a review. Mol Cell Endocrinol. 2011;344(1-2):1-24.

111. O'bryan J, et al (1991) axl, a transforming gene isolated from primary human myeloid leukemia cells, encodes a novel receptor tyrosine kinase. Mol Cell Biol 11(10):5016-5031

112. Paccez JD et al (2013) The receptor tyrosine kinase Axl is an essential regulator of prostate cancer proliferation and tumor growth and represents a new therapeutic target. Oncogene. 32(6):689

113. Nam RK et al (2019) MicroRNA-139 is a predictor of prostate cancer recurrence and inhibits growth and migration of prostate cancer cells through cell cycle arrest and targeting IGF1R and AXL. Prostate. 79(12):1435-1451

114. Zhu Z et al (2014) MicroRNA-145 directly targets the insulin-like growth factor receptor I in human bladder cancer cells. FEBS Lett 588(17):3180-3185

115. Hellawell $\mathrm{G}$ et al (2003) Chemosensitization of human prostate cancer using antisense agents targeting the type 1 insulin-like growth factor receptor. BJU Int. 91(3):271-277

116. Krueckl SL et al (2004) Increased insulin-like growth factor I receptor expression and signaling are components of androgen-independent progression in a lineage-derived prostate cancer progression model. Cancer Res 64(23):8620-8629

117. Nickerson T et al (2001) In vivo progression of LAPC-9 and LNCaP prostate cancer models to androgen independence is associated with increased expression of insulin-like growth factor I (IGF-I) and IGF-I receptor (IGF-IR). Cancer Res. 61(16):6276-6280

118. Wang L-N et al (2013) The miRNA let-7a1 inhibits the expression of insulin-like growth factor 1 receptor (IGF1R) in prostate cancer PC-3 cells. Asian J Androl 15(6):753

119. Pendergast AM (2002) The Abl family kinases: mechanisms of regulation and signaling. Adv Cancer Res. 85(85):51-100

120. Tsuji T (2004) Physiological and pathological roles of a3ß1 integrin. J Membrane Biol. 200(3):115-132

121. Arora S et al (2013) MicroRNA-4723 inhibits prostate cancer growth through inactivation of the Abelson family of nonreceptor protein tyrosine kinases. PLoS One 8(11):e78023

122. Greuber EK et al (2013) Role of ABL family kinases in cancer: from leukaemia to solid tumours. Nat Rev Cancer 13(8):559-571

123. Colicelli J (2010) ABL tyrosine kinases: evolution of function, regulation, and specificity. Sci Signal 3(139):re6-re6

124. Zandy NL (2008) Abl tyrosine kinases mediate intercellular adhesion Duke University

125. Peacock JG et al (2007) The Abl-related gene tyrosine kinase acts through p190RhoGAP to inhibit actomyosin contractility and regulate focal adhesion dynamics upon adhesion to fibronectin. Mol Biol Cell 18(10):3860-3872

126. Qiang XF et al (2014) miR-20a promotes prostate cancer invasion and migration through targeting ABL2. J Cell Biochem 115(7):1269-1276
127. Fizazi K (2007) The role of Src in prostate cancer. Ann Oncol 18(11):1765-1773

128. Ingley E (2012) Functions of the Lyn tyrosine kinase in health and disease. Cell Commun Signal 10(1):1-11

129. Chang CY-M, Kung H-J, Evans CPJN (2007) Nonreceptor tyrosine kinases in prostate. Neoplasia 9(2):90-100

130. Saini S et al (2014) Regulation of SRC kinases by microRNA-3607 located in a frequently deleted locus in prostate cancer. Mol Cancer Ther 13(7):1952-1963

131. Scher HI, Sawyers CL (2005) Biology of progressive, castration-resistant prostate cancer: directed therapies targeting the androgen-receptor signaling axis. J Clin Oncol 23(32):8253-8261

132. Zong Y, Goldstein AS (2013) Adaptation or selection-mechanisms of castration-resistant prostate cancer. Nat Rev Urol 10(2):90-98

133. Bromann PA, Korkaya H, Courtneidge SA (2004) The interplay between Src family kinases and receptor tyrosine kinases. Oncogene 23(48):7957-7968

134. Carver BS et al (2011) Reciprocal feedback regulation of PI3K and androgen receptor signaling in PTEN-deficient prostate cancer. Cancer Cell 19(5):575-586

135. Kinkade CW et al (2008) Targeting AKT/mTOR and ERK MAPK signaling inhibits hormone-refractory prostate cancer in a preclinical mouse model. J Clin Invest 118(9):3051-3064

136. Mulholland DJ et al (2011) Cell autonomous role of PTEN in regulating castration-resistant prostate cancer growth. Cancer Cell 19(6):792-804

137. Liu Y-N et al (2015) Loss of androgen-regulated microRNA 1 activates SRC and promotes prostate cancer bone metastasis. Mol Cell Biol 35(11):1940-1951

138. Yang YA, Yu JJP (2013) EZH2, an epigenetic driver of prostate cancer. Protein Cell 4(5):331-341

139. Xu K et al (2012) EZH2 oncogenic activity in castration-resistant prostate cancer cells is Polycomb-independent. Science 338(6113):1465-1469

140. Shi X-B et al (2015) miR-124 and androgen receptor signaling inhibitors repress prostate cancer growth by downregulating androgen receptor splice variants, EZH2, and Src. Cancer Res 75(24):5309-5317

141. Zhang $\mathrm{H}$ et al (2013) Downregulation of G3BPs inhibits the growth, migration and invasion of human lung carcinoma H1299 cells by suppressing the Src/FAK-associated signaling pathway. Cancer Gene Ther 20(11):622-629

142. Maung K et al (1999) Requirement for focal adhesion kinase in tumor cell adhesion. Oncogene 18(48):6824-6828

143. Liu H et al (2018) Invasion-related circular RNA circFNDC3B inhibits bladder cancer progression through the miR-1178-3p/G3BP2/SRC/FAK axis. Mol Cancer 17(1):161

144. Liu L et al (2016) Long noncoding RNA H19 competitively binds miR-17-5 $p$ to regulate YES 1 expression in thyroid cancer. FEBS $J$ 283(12):2326-2339

145. Yamamoto $\mathrm{H}$ et al (2016) Yes 1 is the key molecule for the resistance to trastuzumab in breast cancer, and dasatinib overcomes the resistance. AACR

146. Chen L, Cao H, Feng Y (2018) MiR-199a suppresses prostate cancer paclitaxel resistance by targeting YES1. World J Urol 36(3):357-365

147. Ottoson NC et al (2001) Cutting edge: T cell migration regulated by CXCR4 chemokine receptor signaling to ZAP-70 tyrosine kinase. J Immunol 167(4):1857-1861

148. Soede RD et al (1999) LFA-1 to LFA-1 signals involve $\zeta$-associated protein-70 (ZAP-70) tyrosine kinase: relevance for invasion and migration of a T cell hybridoma. J Immunol 163(8):4253-4261

149. Richardson SJ et al (2006) ZAP-70 expression is associated with enhanced ability to respond to migratory and survival signals in B-cell chronic lymphocytic leukemia (B-CLL). Blood. 107(9):3584-3592

150. Fu D et al (2016) MiR-631/ZAP70: A novel axis in the migration and invasion of prostate cancer cells. Biochem Biophys Res Commun 469(3):345-351

151. Brauer PM, Tyner AL (2010) Building a better understanding of the intracellular tyrosine kinase PTK6—BRK by BRK. Biochimica et Biophysica Acta (BBA)-Rev. Cancer 1806(1):66-73

152. Zheng Y, Tyner AL (2013) Context-specific protein tyrosine kinase 6 (PTK 6) signalling in prostate cancer. Eur J Clin Invest. 43(4):397-404 
153. Wozniak DJ et al (2017) PTEN is a protein phosphatase that targets active PTK6 and inhibits PTK6 oncogenic signaling in prostate cancer. Nature communications 8(1):1-13

154. Cagle P et al (2019) MicroRNA-214 targets PTK6 to inhibit tumorigenic potential and increase drug sensitivity of prostate cancer cells. Sci Rep 9(1):1-13

155. Yeasmin S et al (2011) MKK4 acts as a potential tumor suppressor in ovarian cancer. Tumor Biol 32(4):661-670

156. Ishikawa M et al (2010) Functional and clinicopathological analysis of loss of MKK4 expression in endometrial cancer. Oncology 79(3-4):238-246

157. Wan X et al (2016) Androgen-induced miR-27A acted as a tumor suppressor by targeting MAP2K4 and mediated prostate cancer progression. Int J Biochem Cell Biol 79:249-260

158. Zhu Y et al (2018) MicroRNA-136 inhibits prostate cancer cell proliferation and invasion by directly targeting mitogena-ctivated protein kinase kinase 4. Mol Med Rep 17(3):4803-4810

159. Avruch J et al (2001) Ras activation of the Raf kinase: tyrosine kinase recruitment of the MAP kinase cascade. Recent Prog Horm Res 56:127-155

160. Ahmad I et al (2011) Ras mutation cooperates with $\beta$-catenin activation to drive bladder tumourigenesis. Cell Death Dis 2(3):e124-e124

161. Moon RT et al (2004) WNT and $\beta$-catenin signalling: diseases and therapies. Nat Rev Genet 5(9):691-701

162. Hirata $\mathrm{H}$ et al (2012) MicroRNA-1826 targets VEGFC, beta-catenin (CTNNB1) and MEK1 (MAP2K1) in human bladder cancer. Carcinogenesis 33(1):41-48
163. Khan $\mathrm{N}$ et al (2008) Cancer chemoprevention through dietary antioxidants: progress and promise. Antioxid Redox Signal 10(3):475-510

164. Fremont $L$ (2000) Biological effects of resveratrol. Life Sci 66(8):663-673

165. Maxwell S, Cruickshank A, Thorpe GJTL (1994) Red wine and antioxidant activity in serum. Lancet 344(8916):193-194

166. Harper CE et al (2007) Resveratrol suppresses prostate cancer progres sion in transgenic mice. Carcinogenesis 28(9):1946-1953

167. Bitomsky N, Böhm M, Klempnauer K-HJO (2004) Transformation suppressor protein Pdcd4 interferes with JNK-mediated phosphorylation of c-Jun and recruitment of the coactivator p300 by c-Jun. Oncogene 23(45):7484-7493

168. Egan SM et al (2017) miR-30e* is overexpressed in prostate cancer and promotes NF-KB-mediated proliferation and tumor growth. Oncotarget 8(40):67626

169. Wang $\mathrm{N}$ et al (2015) Autocrine activation of $\mathrm{CHRM} 3$ promotes prostate cancer growth and castration resistance via CaM/CaMKK-mediated phosphorylation of Akt. Clin Cancer Res 21(20):4676-4685

170. Zheng X-M et al (2019) MicroRNA-30e inhibits adhesion, migration, invasion and cell cycle progression of prostate cancer cells via inhibition of the activation of the MAPK signaling pathway by downregulating CHRM3. Int J Oncol 54(2):443-454

\section{Publisher's Note}

Springer Nature remains neutral with regard to jurisdictional claims in published maps and institutional affiliations.

\section{Submit your manuscript to a SpringerOpen ${ }^{\circ}$ journal and benefit from:}

- Convenient online submission

- Rigorous peer review

- Open access: articles freely available online

- High visibility within the field

- Retaining the copyright to your article

Submit your next manuscript at $\boldsymbol{\nabla}$ springeropen.com 